\title{
Facing the Challenges of Supercooled Large Droplet Icing: Results of a Flight Test Based Joint DLR-Embraer Research Project
}

\author{
Christoph Deiler, Per Ohme, and Christian Raab German Aerospace Center (DLR)
}

Celso Mendonca and Daniel Silva Embraer

Citation: Deiler, C., Ohme, P., Raab, C., Mendonca, C. et al., "Facing the Challenges of Supercooled Large Droplet Icing: Results of a Flight Test Based Joint DLR-Embraer Research Project," SAE Technical Paper 2019-01-1988, 2019, doi:10.4271/2019-01-1988.

\section{Abstract}

T

oday's airplanes are well equipped to cope with most common icing conditions. However, some atmospheric conditions consisting of supercooled large droplets (SLD) have been identified as cause of severe accidents over the last decades as existing countermeasures even on modern aircraft are not necessarily effective against SLD-ice. In 2014, the new Appendix O to the certification regulations (FAR Part 25 / CS-25) had been issued to guarantee the safe operation of future airplane when encountering SLD conditions. But as the SLD topic is quite new for the majority of aircraft manufacturers and research institutes in a same way, DLR (German Aerospace Center) and Embraer established a joint research cooperation in 2012 to obtain a better understanding of the distinct influences of SLD-ice shapes on aircraft characteristics and to evaluate proper ways for future airplane certification under App. O. Furthermore, one additional scientific goal of the cooperation was to develop and test new tools for the in-flight monitoring of aircraft characteristics as well as the on-board identification of simulation models. During the 4 years of the project, a distinct way to better understand icing-induced degradations on a specific aircraft was followed: first, data of the clean aircraft was gathered in flight test to identify a dynamic simulation model as base for the subsequent evaluations. Second, data of test flights with artificial App. C ice configurations were analyzed and used for the development of distinct modifications of the base aircraft simulation model; a first evaluation of the icing-induced changes of aircraft characteristics was conducted. Third, after the generation of SLD-ice shapes, wind tunnel testing and flight clearance, a second flight test campaign with these artificial SLD-ice shapes delivered the data for an additional model modification and identification. The results of the final data and model evaluation provide the observable degradation of SLD-ice in flight, which is well comparable to results obtained from the App. C ice configurations.

\section{Introduction}

cing can have hazardous effects on airplane performance characteristics. It can also be a limiting factor for the safe flight envelope. Icing-induced change of the aircraft's dynamic behavior and potential premature stall raise the need for pilot situational awareness and an adaption of any aircraft control strategy. During the last decades, various accidents worldwide have shown the severity of icing related degradations as well as pilots' difficulties to cope with changes in aircraft behavior $[1,2]$. One major cause for these accidents was that with rising air traffic aircraft were increasingly operated in certain icing conditions containing supercooled large water droplets (SLD) against which current aircraft were not protected. The certification of (modern) transport aircraft for flight into icing conditions was mainly based on the certification requirements given in the so called App. C to e.g. CS-25. But with the identified hazard to fixed-wing aircraft resulting from the supercooled large droplets the aviation agencies issued the new App. O to the existing certification requirements. From now on, manufacturers of newly developed transport airplanes must prove that the airplane is also safe for flight into the even more hazardous atmospheric icing conditions.

The new certification requirements led to a demand for acceptable means of compliance and consequently the question about a way to safely demonstrate the remaining aircraft capabilities in flight for the case of SLD icing. These icing conditions can pose a high risk to the aircraft and crew, which results in a large effort to assure aircraft safety during flight test. Hence, it is mandatory to analyze the possible aircraft performance and control degradation introduced by SLD icing and also monitor the aircraft's remaining capabilities during the complete test flight. The distinct impact of SLD ice on the overall aircraft characteristics is not easy to predict and still an aspect of current aviation research. As the overall need for a better understanding of the SLD-icing effects on aircraft was identified as a research gap, a German national funded research project named SuLaDI (Supercooled 
Large Droplet Icing) was established between DLR and TU-Braunschweig (2011-2016). In parallel, a joint research activity between DLR and Embraer was established between 2012 and 2016 to further investigate the icing degradation of aircraft in general but with a distinct view to SLD conditions. The major advantage of this research cooperation was the focus on flight test and flight data analysis with respect to different icing cases (App. C and App. O), which was no part of SuLaDI but is highly important to answer some question about the distinct effects of icing on aircraft characteristics. Furthermore, one additional goal of this cooperation was to develop new system-identification methodologies to monitor the icing degradation online and directly identify aircraft simulation models containing the icing-related degradations in-flight.

In general, during the flight through icing conditions, ice can accumulate on airframe parts facing the inflow e.g. wing or stabilizer leading edges, aircraft nose or engine intakes if these surfaces are not protected by any countermeasures. The main aerodynamic degradation is expected to be caused by wing ice accretions and manifests itself in a reduced stall angle of attack and increased drag. These accumulations can form different shapes depending on e.g. atmospheric conditions and aircraft geometry. The general aerodynamic influence is outlined for example in the "AGARD Report 344" [3] and given in Figure 1. In the past, these icingeffects had been investigated in various studies for different airfoils and icing cases (e.g. Refs. $\underline{3}-\underline{5}$ ) as well as for the complete aircraft (e.g. Refs. $\underline{6}-\underline{9})$.

This paper shows the supplementary results of the joint DLR-Embraer research on aircraft icing which make a contribution to some of the key scientific aspects related to aircraft icing, e.g. aircraft operational limitations and behavior with accumulated ice on various surfaces. It presents the approach used to draw the final conclusions about the degrading effects of SLD-icing on a distinct already existing aircraft - a Phenom 300 prototype (see Figure 2):

1. The development of a basic (clean) aircraft simulation model including flight test and data analysis, with the first test of online system-identification tools;

2. Flight tests data analysis of flights with artificial App.C ice shapes;

3. SLD-ice shape generation and wind tunnel testing;

FIGURE 1 Expected aerodynamic degradation due to icing [3] (lift curve and drag polar).

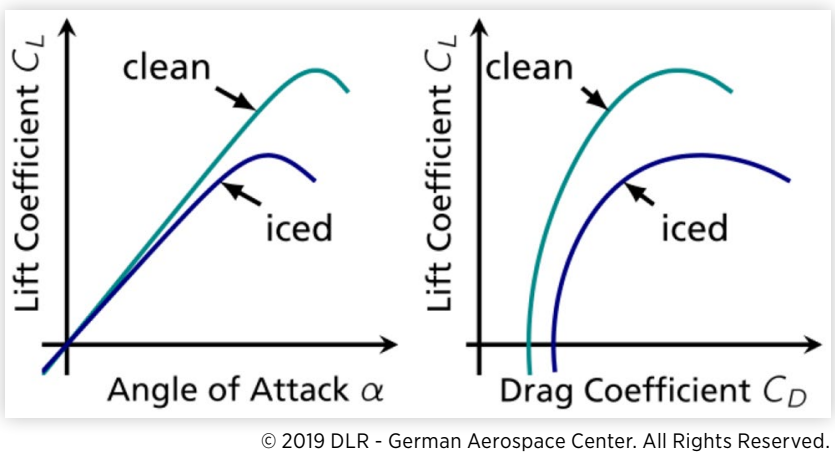

FIGURE 2 EMBRAER Phenom 300 test aircraft.

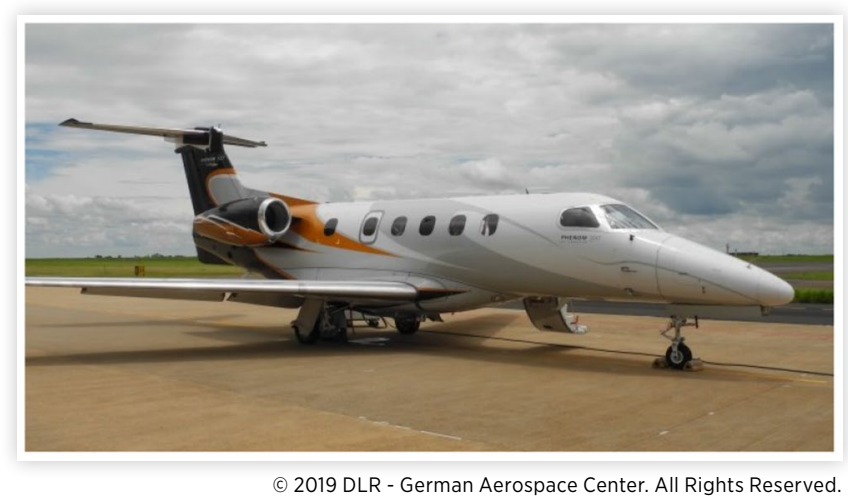

4. Flight test with artificial SLD-ice shapes, usage of online

system-identification tools for real-time data analysis;

5. Post-flight data analysis together with a comparison of all results.

Finally, the paper gives some conclusions regarding the results of the SLD-ice flight tests.

\section{Online System- Identification Tools}

System-identification techniques are commonly used in engineering to develop simulation models of an arbitrary complex system based on measured data during a dedicated test scenario. With regard to an application on aerospace systems this means that during a certain test of e.g. a fixed-wing aircraft, a helicopter or a rocket, special maneuvers are carried out, the system's reaction is measured and the simulation model structures and parameters are modified to guarantee the best possible match of the model outputs to the measurements $[10,11]$. Two different new system-identification tools had been developed by DLR for the real-time flight data analysis and in-flight model parameters estimation task. Both tools are based on different methodologies and provide different advantages for each of the tasks. The first tool called RAPIT (Rapid Aerodynamic Parameter Identification Tool) works in the frequency domain and allows an estimation of aerodynamic stability and control parameters in near realtime during the flight test maneuvers and compares them to reference values [12]. The second software tool is called FITLAB-Online and uses a maximum-likelihood (outputerror) method in the time domain for the estimation of aerodynamic model parameters; this tool is based on the DLR parameter estimation software tool FITLAB [13]. A maximumlikelihood method defines the "most likely parameter vector" as the parameter combination that maximizes the likelihood to have obtained the available measurements with a given model. Output error means that the measured outputs of a dynamic system are matched against the observed outputs of a complex nonlinear (aircraft) simulation model [10]. One of the features of FITLAB-Online is that the tool cuts flight data 
automatically into time slices of different maneuvers which are subsequently batch-processed for the estimation of the model parameters. Compared to the RAPIT method the FITLAB-Online algorithm allows e.g. estimating parameters of non-linear aerodynamic models valid for the whole flight envelope. Results are available within minutes after the maneuver and can already be analyzed during the debriefing after flight. For a further insight on the tools, the data handling and detailed results of the corresponding tests during the flight test campaigns, which goes beyond the scope of this paper, the reader is referred to Ref. 14 .

\section{Basic Aircraft Model}

Embraer provided a prototype of the Phenom 300 business jet as test aircraft. It is a twin jet-engine aircraft with a horizontal stabilizer in T-tail configuration, a maximum take-off weight of $8.3 \mathrm{t}$, a wingspan of $16 \mathrm{~m}$ and a conventional reversible flight control system. The aircraft was equipped with standard air data sensors and an inertial reference platform.

The basic aircraft motion is represented by a six degree of freedom dynamic model. A two-point aerodynamic model implementation [15] separating wing and horizontal tail influences is used to represent the unsteady nonlinear aerodynamics of the longitudinal motion. The separation of wing and tail enables to easily consider nonlinearities like downwash or flow-transit effects between wing and tail. To represent an unsteady nonlinear stall behavior by the two-point model, the equations were extended according to the formulations in literature [16]. The lateral motion aerodynamics model formulation - a state of the art derivative model for the aerodynamic coefficients - can be found in [17].

\section{Flight Test Campaign}

The flight test campaign was conducted in December 2014 on Embraer's flight test site in Gavião Peixoto, Brazil. The flight test program contained at least five different state-of-the-art system identification maneuvers [10], performed at 9 different test points within the aircraft's normal flight envelope as given in Table 1.

TABLE 1 Test points for flight test campaign with clean aircraft.

\begin{tabular}{|l|l|l|}
\hline Test point. & Indicated airspeed & Altitude \\
\hline 1 & $250 \mathrm{kt}$ & $20,000 \mathrm{ft}$ \\
\hline 2 & $250 \mathrm{kt}$ & $16,000 \mathrm{ft}$ \\
\hline 3 & $160 \mathrm{kt}$ & $16,000 \mathrm{ft}$ \\
\hline 4 & $130 \mathrm{kt}$ & $16,000 \mathrm{ft}$ \\
\hline 5 & $170 \mathrm{kt}$ & $20,000 \mathrm{ft}$ \\
\hline 6 & $135 \mathrm{kt}$ & $20,000 \mathrm{ft}$ \\
\hline 7 & $250 \mathrm{kt}$ & $9,000 \mathrm{ft}$ \\
\hline 8 & $170 \mathrm{kt}$ & $9,000 \mathrm{ft}$ \\
\hline 9 & $130 \mathrm{kt}$ & $9,000 \mathrm{ft}$ \\
\hline
\end{tabular}

To reduce the effort and costs for the first campaign and cope with heavy thunderstorms by the time, it was decided to only do one single flight for the whole flight test program. This flight resulted in 82 data sets of the following flight test maneuvers:

- elevator 3-2-1-1 multistep inputs,

- elevator pulse input to excite the phugoid motion,

- bank-to-bank maneuver using ailerons and roll spoilers.

- bank-to-bank maneuver using ailerons only, and

- rudder doublet maneuvers to excite the Dutch-roll.

All maneuvers started from a trimmed steady horizontal flight condition as specified by the test point definition. The resulting flight data sets include measurements of 1) translational accelerations; 2) rotational rates; 3) aircraft attitude; 4) true airspeed, angle of attack, and angle of sideslip; 5) geographic position and altitude; and 6) control surface deflections. Moreover, post-flight calculations of center of gravity, moments of inertia, aircraft mass, and engine thrust are available. The rotational accelerations were calculated by numerical differentiation of the measured rotational rates.

During flight test with the clean aircraft the flight crew consisted of two pilots, two Embraer flight test engineers and one experimental engineer from DLR. For the first flight test, the data was monitored and processed on board with a laptop connected to the aircraft's flight data network, but it had been also possible to send the data to a telemetry station on ground, if required.

\section{System-Identification Results}

An output error method in the time domain (an iterative maximum likelihood method) was herein selected for parameter estimation. The method was widely used for aircraft system-identification in the past and showed good performance in different applications $[19, \underline{20}]$.

Figure 3 shows the time histories of an elevator 3-2-1-1 multistep input maneuver. The dynamic aircraft excitation by the elevator deflection (top graph) causes a reaction in longitudinal and vertical acceleration (next two graphs, from top to bottom) as well as a change of pitch rate and attitude (next two graphs, from top to bottom). The aircraft's airspeed remains nearly constant while the variation in the angle of attack (bottom graph) is well noticeable (exciting the short period dynamics). The simulated outputs of the identified base model match very well the measurements in terms of steady and dynamic behavior. With the base aircraft model identified, the model can be used for further evaluations by e.g. comparison of the influence of different ice cases to the base (clean) aircraft.

\section{Analysis of Flight Tests with Artificial App. C Icing}

Data of former test flights with two different artificial App.C ice configurations were available for the first analysis in the project. The data evaluation allows drawing general 
FIGURE 3 Time history comparison of identified basic aircraft model simulation outputs and corresponding measurements for elevator 3-2-1-1 multi-step input maneuver.

Seasurement
elevator
longitudinal
acceleration

conclusions on the changes of aircraft characteristics for "classical" (App. C) ice configurations. This was necessary to obtain an additional baseline for the later-on comparison with the SLD-ice flight results. Hence, the App. C ice flight test data was used to identify different aerodynamic simulation models and evaluated concerning the detectable changes of flight performance, dynamics and handling/flight qualities, which is briefly presented in hereafter.

\section{Model Formulation}

An aerodynamic $\Delta$-model formulation which accounts for additional icing effects on aerodynamics is formulated as an extension of previously developed and validated simulation models for the specific test aircraft. It enables to simulate the aerodynamic performance changes due to additional forces and moments related to icing, which are calculated by the $\Delta$-model in parallel to the basic aircraft's aerodynamics and summed up afterwards (see Figure 4). During this process the $\Delta$-model is directly connected to the basic aircraft's aerodynamic model to use some information about the basic aerodynamics if necessary.

The basic idea of the model extension is to use linearly altered parameters for icing-induced aerodynamic changes
FIGURE 4 Aerodynamic model inside the aircraft simulation with the $\Delta$-model extension to cover the icing-effects on the aircraft behavior from [18]; the overall aerodynamic model is dependent on the model parameters, the aircraft motions, control inputs and atmospheric parameters respectively the environment.

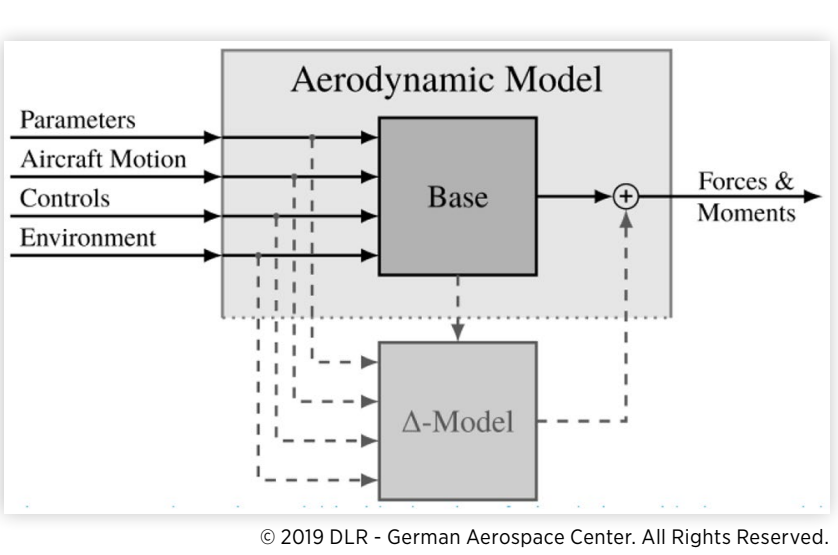

in aircraft simulation. The application of such a parameter extension for the modeling of icing effects was first introduced by Bragg [21] around the turn of the millennium. An arbitrary model parameter $\mathrm{P}$ including a basic model part $\mathrm{P}_{\text {base }}$ and an additional $\Delta$-model part $\Delta \mathrm{P}_{\text {ice }}$ can be expressed as

$$
P=\left(1+k_{P}\right) \cdot P_{\text {base }}+d_{P}=P_{\text {base }}+\Delta P_{\text {ice }}
$$

with the additional factor $k_{P}$ and the offset $d_{P}$ to model the degraded aircraft aerodynamics. For an arbitrary aerodynamic model coefficient $C(\cdot)$ depending on an extended parameter $\mathrm{P}$ this separation yields in general:

$$
\begin{aligned}
C_{(\cdot)}(P) & =C_{(\cdot)}\left(P_{\text {base }}+\Delta P_{\text {ice }}\right) \\
& =\left(C_{(\cdot)}\left(P_{\text {base }}\right)\right)_{\text {base }}+\Delta\left(C_{(\cdot)}\left(P_{\text {base }}+\Delta P_{\text {ice }}\right)\right)_{\text {ice }}
\end{aligned}
$$

This coefficient separation can lead to various different formulations of the $\Delta$-model depending on the structure of the base aerodynamic model and therefore the considered aircraft. Moreover, the $\Delta$-model structure may vary with the objectives of the later usage. For example, a $\Delta$-model implementation accounting only for icing effects on the longitudinal motion might be much simpler than a $\Delta$-model covering changes in all six degrees of freedom. Such a formulation for the longitudinal aircraft motion as well as the corresponding parameters resulting from system-identification is given in [22]. More complex $\Delta$-models were developed in $[18, \underline{23}]$ accounting for icing-induced aerodynamic degradation and corresponding effects on the complete aircraft motion. Furthermore, they also allow predicting asymmetric icing effects due to local ice accretion. Similar to the strip method to simulate the aircraft reaction due to the impact of inhomogeneous flow fields [24], the $\Delta$-models were formulated to individually describe the degrading influence on the local wing aerodynamics. 


\section{Investigated Ice Shapes and Flight Test Data}

The available flight test data was used to estimate $\Delta$-model parameters for two different ice configurations [18]: one configuration includes run-back ice on the wing representing a normal operation with the ice protection system in minimum power mode; and the other a wing leading-edge ice shape to simulate an escape from an annunciated ice protection system (IPS) failure scenario during a holding. For the run-back ice case, 34 data sets (about 1360 s recording time) from previous certification flight tests were used containing different dynamic maneuvers. These maneuvers include for example rudder doublets and approaches to stall without complete flow separation and reattachment. Because of flight safety reasons the higher angle of attack region - where a complete flow separation is anticipated - was not entered. Furthermore, six data sets of maneuvers from the leading-edge ice flight test with a data length of $280 \mathrm{~s}$ were available. These data mainly contain elevator pushover and aileron roll response maneuvers with no direct intention to approach stall. All data sets contained the same signals which were already measured during clean aircraft test flights with similar quality and sample rate.

\section{Data Analysis}

First, the available flight data were analyzed to get an impression about the expectable icing-related aerodynamic degradation. Second, an identification of the corresponding dynamic aircraft simulation models was performed with the same flight data. The aerodynamic degradation caused by icing was then evaluated by comparing the output of the newly identified models with the clean aircraft model's results.

The corresponding change of the aircraft drag coefficient for each ice case is given in Figure 5, for which the coefficients are calculated from the flight measurements [14]. The form of

\section{FIGURE 5 Drag polar computed from measurements as a} result of flight tests with different artificial App.C ice shapes

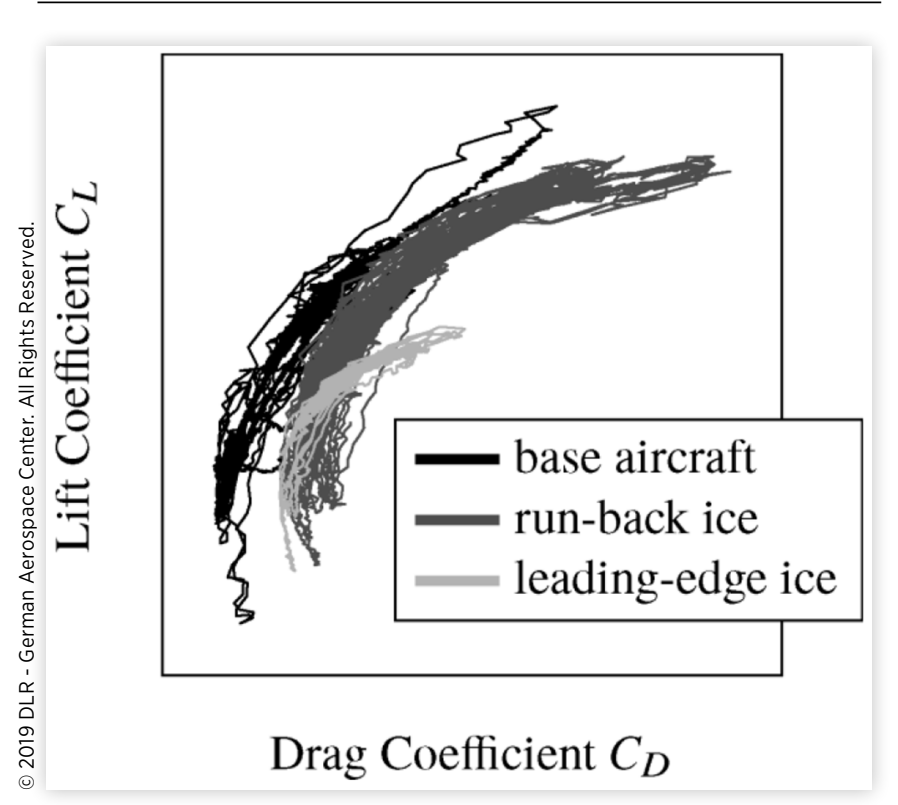

(c) 2019 DLR - German Aerospace Center. All Rights Reserved.
FIGURE 6 Changes of lift and drag curves for different ice cases; aerodynamic model data (after identification)

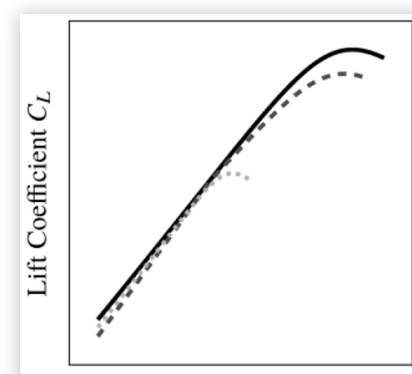

Angle of Attack $\alpha$

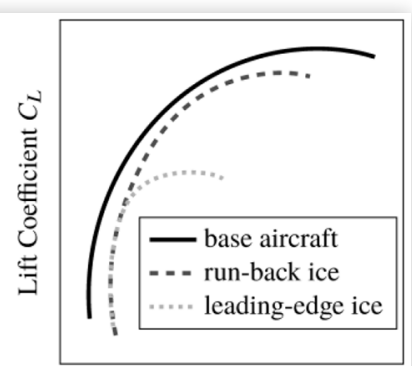

Drag Coefficient $C_{D}$ (c) 2019 DLR - German Aerospace Center. All Rights Reserved.

the drag polar is completely different in both ice cases; for the run-back ice, the drag increase at medium lift coefficients is smaller than for leading-edge ice, which shows a stronger curvature and consequently higher drag coefficient at comparable lift coefficients. The lift and drag curves calculated with the identified aerodynamic model parameters are given in Figure 6. Note that the "base aircraft" corresponds to the clean aircraft model whereas for both ice cases a combination clean aircraft and $\Delta$-model is used as described above. Because of the match between the measurements and the simulation after identification was very good (see Ref. 18), these curves provide similar results as Figure 5 concerning the aerodynamic degradation. Therefore, the corresponding flight performance changes are expected to be different for each ice case at similar flight conditions.

For example, these changes are shown in Figure 7 in form of the change in the thrust-to-weight ratio TWR at a distinct altitude and variable indicated airspeed for the different App. C ice cases. It becomes clearly visible that the aerodynamic degradation yields the expectable limitation of the aircraft's operational envelope. The required thrust-to-weight ratio significantly increases for indicated airspeeds above $200 \mathrm{kt}$ in both ice cases. Because of the well comparable identified increase in zero-lift drag for run-back and leading-edge ice the maximum achievable airspeed is very similar for both

\section{FIGURE 7 Limited flight performance under icing} conditions on the example of required thrust-to-weight ratio and specific excess power: results for base aircraft and two different ice cases at identical altitude and aircraft mass

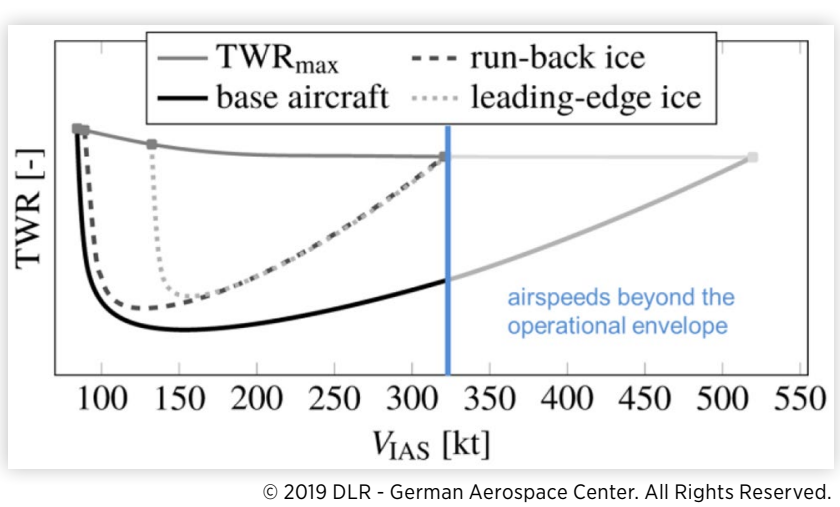


ice cases and also far below the base aircraft's limitation. The icing-induced premature stall behavior particularly in case of leading-edge ice (see Figure 6) and the corresponding drag increase cause also a restriction of the minimum airspeed, which could be theoretically achieved in steady flight with the available engine thrust. But with respect to the icing-induced stall speed increase, the resulting value is below the safe envelope for the current ice case.

Within the scope of the data analysis the changes of aircraft dynamics and handling qualities due to icing are of high interest. The models - basic aircraft model with the individual $\Delta$-model extension for each ice case - were analyzed concerning the change of the aircraft's dynamic modes. It revealed that mainly the aircraft's phugoid, Dutch roll and roll mode are changing under the investigated icing influence. But, these changes do not significantly affect the aircraft's handling qualities, which could be proven by evaluation of numerical handling/flight qualities criteria. A more detailed description of this evaluation is given in Ref. $\underline{25}$. Moreover, during the corresponding flight test no significant changes of aircraft controllability and dynamic characteristics (except changes related to the drag increase) were noticeable for the pilots.

\section{SLD-Ice Shapes Generation}

Numerical prediction of SLD ice formation still lack validated tools and procedures [26]. However, based on experimental observations and knowledge of the available numerical tools limitations, a simplified approach to emulate an SLD ice formation for protected and unprotected regions was proposed. After definition of the ice formations, the corresponding impact on controllability and the reduction of stall margin was evaluated in the wind tunnel to mitigate safety risks to the aircraft during flight test with these ice formations.

\section{Numerical Calculation of SLD-Ice Shapes}

In order to evaluate the impact of an SLD encounter a 3D simulation was performed to estimate the pressure coefficient distribution, convective heat transfer over the surfaces and the impingements limits for the SLD envelopes. The full SLD spectrum was simulated, i.e. freezing drizzle (FZDZ) and freezing rain less than and greater than 40 microns with drop distribution as given in Ref. [26]. Additional considerations were adopted on the estimation of the collection efficiency: for this purpose a threshold of $15 \%$ was established to define the impingement limits as a criteria based on the results in literature [27]. Figure 8 shows the collection efficiency contour plot for FZDZ $>40 \mu \mathrm{m}$ considering this threshold criterion.

The prediction of ice formation requires the determination of some relevant parameters as exposure time, flight altitude, ambient temperature, angle of attack, flight speed
FIGURE 8 Phenom 300 water collection efficiency contours for FZDZ>40 $\mu \mathrm{m}$.

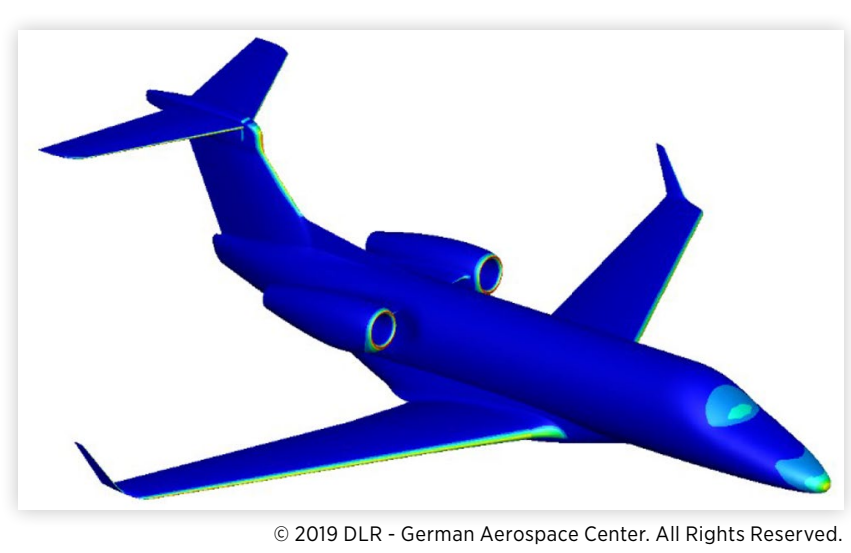

and supercooled water range. For the purpose of the study, a 15 minutes steady flight was established considering that the aircraft maintains in the same configuration as for the initial App. C ice predictions. Figure 9 shows the ice estimations for an arbitrary section of the wing with different ice accretions resulting from different atmospheric conditions. The procedure to estimate the ice formation followed the process reported in Ref. 28 applying a 3-level correction in order to obtain a 3D representation of the ice formation on unprotected regions. The results match experimental data and the results of numerical predictions as reported in Ref. $\underline{29}$, which gives the results of an evaluation on the effects of scaling and MVD variation on ice formation for an airfoil.

Based on the results obtained from the relatively long ice exposure, an SLD-envelope with FZDZ greater than $40 \mu \mathrm{m}$ was considered as the best representation for the desired ice encounter following some rule of engineering judgement.

Furthermore, additional considerations were made for the residual ice formation, which is represented by a spanwise ridge ice shape streamwise behind the protected areas (runback ice). Typically, the critical condition for a hot-air ice protection would depend on very cold environment. However, this condition would result in rime ice formations for unprotected regions which tend to be less severe than glaze ice shapes [31]. Nevertheless, a combination of scenarios was deemed acceptable to predict the ice shapes for unprotected

\section{FIGURE 9 Ice formation on a 2D section over the wing} (not to scale).

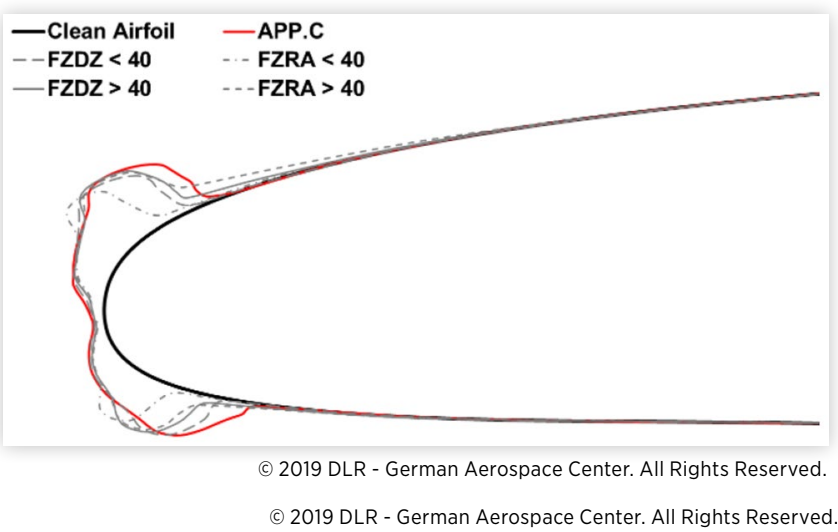


FIGURE 10 Artistic illustration of spanwise ridge ice formations (not to scale).

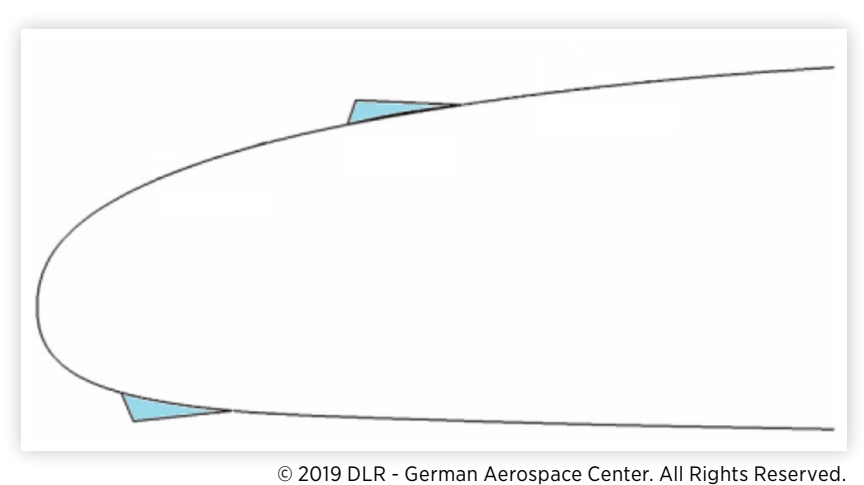

and protected regions. Considering those assumptions, a representative $3 \mathrm{D}$ thermodynamic model for the hot-air ice protection system [32] was developed in order to predict the residual ice on the wing. Hence, the energy level of the aircraft's ice protection system was reduced to simulate a running wet condition. Note, that such case and condition is not representative for the actual aircraft and ice protection system design but necessary for the sake of this study.

From the simulation, it was possible to define the freezing locations and the residual ice growth rates both on upper and lower wing surfaces. Moreover, in order to define the shape of the residual ice several assumptions based on the work presented in [33] were made. Figure 10 artistically illustrates the resulting residual ice formation on the airfoil.

This prediction of the residual ice represents the ice formation expected for the proposed virtual ice encounter. In addition, two different ice positions were suggested on the upper surface to assess the influence of residual ice location on aircraft performance. Figure 11 shows these additional positions: the forward most location (position 1) represents an additional degradation of the ice protection system; the intermediate location (position 2) indicates the output from the thermodynamic evaluation; and the aftermost location (position 3) is related to the end of the protected area. In addition to the triangular shapes an additional 1 inch quarterround ice shape located at position 3 was proposed. It results

FIGURE 11 Artistic illustration of spanwise ridge ice formations at different streamwise positions on the airfoil (not to scale).

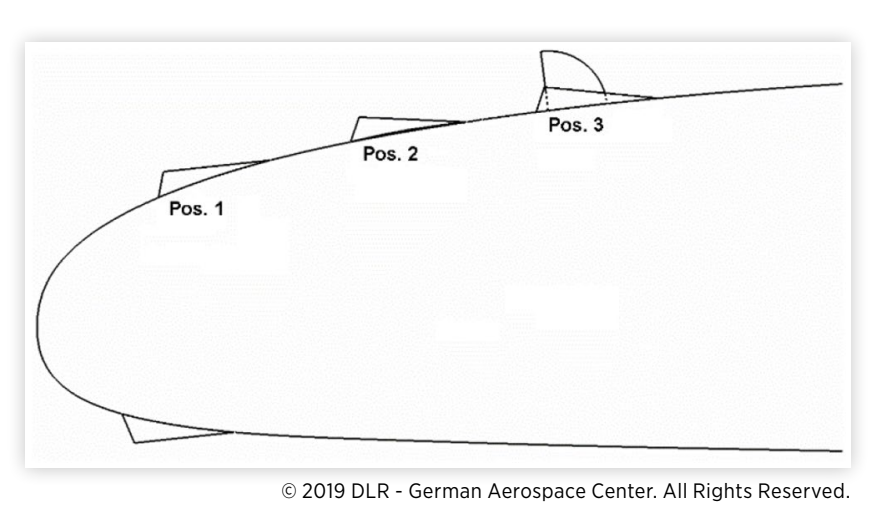

from the fact that usually the 1 inch quarter-round geometry is associated with a simplified representation of SLD ice, predominantly for de-icing ice protection systems as inflatable boots.

\section{Dry Air Wind Tunnel Testing with Full Subscale Model}

The aircraft's dynamics characteristics, i.e. its dynamic stability and controllability, can be significantly affected by ice accretion on the airframe. This potential degradation is strongly related to the form of the ice shape and its position on the airframe, especially on the aerodynamically relevant surfaces (wing, horizontal and vertical tailplane). In consequence, a wind tunnel test prior to the actual flight test is necessary to assess the impact of simulated ice shapes on the aircraft aerodynamics. With these results, the most relevant stability and control characteristics can be evaluated in order to establish the flight conditions in which a safe flight can be guaranteed considering the specific ice shapes on the aircraft.

To evaluate the distinct impacts of a (simulated) SLD ice encounter on the aircraft an extensive test at the TsAGI T-128 dry air wind tunnel was performed. The main objectives of this test were to

- test candidate SLD ice shapes configurations to be used on the Phenom 300 flight test campaign with regard to the overall goal to evaluate the developed online systemidentification tools for assessing the degraded aircraft characteristics in flight;

- obtain the clearance for the flight test campaign (from a safety point of view) by selecting a safe SLD ice shape configuration resulting in a safe flight test envelope;

- evaluate other/additional ice shape configurations in terms of their impact on the aircraft aerodynamics in order to improve Embraer's current theoretical and computational methods employed for the estimation of aerodynamic effects due to ice accretion on an aircraft.

The definition of the wind tunnel test matrix took relevant aspects of the aircraft operation into account. For example, flight configurations as cruise, take-off and landing were simulated to ensure all necessary information required to allow the flight-test with the distinct artificial SLD-ice shapes. Hence, the test matrix was designed to evaluate several aspects as longitudinal characteristics, aileron and rudder effectiveness, sideslip effects, downwash at the horizontal tail and overall lift and drag characteristics. An example of the tunnel test results is given in Figure 12. It indicates the lift degradation resulting from different location of the upper ridgeice shape.

The results show that the chordwise position for installing the SLD ice shape has great impact on the icing-related aerodynamic degradation: moving the ice towards the trailing edge reduce its impacts on the wing stall (flow separation) and neutral-point position. 
FIGURE 12 Degrading effect of upper wing ice shape location on the lift coefficient.

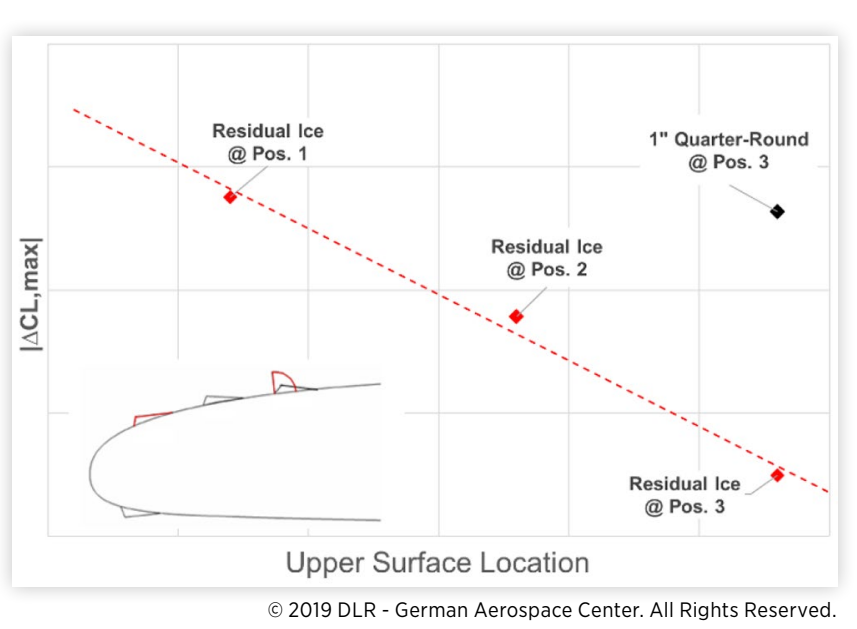

As expected, the quarter-round ice shape configuration leads to the most severe degradation. This degradation can be summarized as

- a decrease of about $35 \%$ of the maximum lift coefficient;

- a drag increase of about $150 \%$;

- a destabilizing shift of the neutral-point equivalent to $8 \%$ of the reference chord;

- a significant roll-off starting at an angle of attack of 5 degrees, with rolling moment coefficient reaching approximately $25 \%$ of the available aileron control efficiency (referenced to the case with residual ice at position 1 in Figure 11 and an angle of attack of 10 degrees).

Based on the wind tunnel results the residual ridge ice at position 1 was selected for flight-test. The decision was based on the fact that this configuration caused a similar level of maximum lift degradation compared to the quarter-round ice but recovered the aileron effectiveness margin at low angle of attack.

\section{Flight Test Campaign with Artificial SLD-Ice Shapes}

With the definition of SLD-ice shapes and the flight clearance after the dry-air wind tunnel test with the Phenom 300 model, the flight test campaign was conducted in November 2015. The flight tests took also place at Embraer's flight test site in Gavião Peixoto.

\section{SLD-Ice Shapes on Flight Test Aircraft}

For the flight tests, artificial ice shapes were fabricated in full scale and glued to the aircraft skin. Three different aircraft configurations were foreseen for the flight test program:
1. Low-Risk SLD: Artificial ice on the radome, winglets and on the wing upper and lower surface except for the wing area around the ailerons (SLD I).

2. Incremental SLD: Artificial ice on the radome, winglets and on the wing upper and lower surface including the wing area around the ailerons (SLD II).

3. Nominal SLD: Artificial ice on the radome, engine pylons, winglets and on the wing upper and lower surface including the wing area around the ailerons (SLD III).

\section{Flight Test Campaign}

System-identification maneuvers were performed at three different altitudes and two different velocities according to the test point definitions listed in Table 2, in order to investigate the aircraft handling characteristics and its performance. The flight test consisted of the same maneuvers already performed with the clean aircraft for basic model identification as described above. All maneuvers started from a trimmed steady horizontal flight condition as specified by the test point definition. The low speed limit of $170 \mathrm{kt}$ indicated airspeed was established after analyzing wind tunnel experiments, which resulted in an increase of the stall speed by a factor of nearly 1.3 for configurations with artificial ice shapes. During all flights with the SLD-ice shapes a telemetry link was used to send the data to a ground station because these flights were classified as "high risk" and only a minimum crew of two pilots and one flight test engineer were allowed onboard. Therefore, the DLR engineers were operating the developed online system-identification tools for monitoring the aircraft characteristics during the whole flight on ground with live data. Via a direct radio link to the flight test aircraft, the crew could be informed about the current flight performance and if necessary about any critical divergence from the nominal flight behavior.

Monitoring of the lateral controllability was of particular interest for the flight test crew because wind tunnel experiments with the SLD-ice shapes showed flow separation on the outboard wing area near the ailerons at high angles of attack. For this reason, first a low risk configuration (SLD I) with no ice shapes in front of the ailerons was flown and then a configuration (SLD II) with the wings fully equipped with shapes. Furthermore, a special maneuver was performed prior to the typical system-identification maneuvers. The aircraft was accelerated to $210 \mathrm{kt}$ indicated airspeed and bank-to-bank

TABLE 2 Test points for flight test campaign with artificial SLD-ice shapes.

\begin{tabular}{|l|l|l|}
\hline Test point & Indicated airspeed & Altitude \\
\hline 1 & $170 \mathrm{kt}$ & $10,000 \mathrm{ft}$ \\
\hline 2 & $220 \mathrm{kt}$ & $10,000 \mathrm{ft}$ \\
\hline 3 & $170 \mathrm{kt}$ & $15,000 \mathrm{ft}$ \\
\hline 4 & $220 \mathrm{kt}$ & $15,000 \mathrm{ft}$ \\
\hline 5 & $170 \mathrm{kt}$ & $20,000 \mathrm{ft}$ \\
\hline 6 & $220 \mathrm{kt}$ & $20,000 \mathrm{ft}$ \\
\hline
\end{tabular}

(c) 2019 DLR - German Aerospace Center. All Rights Reserved. (c) 2019 DLR - German Aerospace Center. All Rights Reserved. 
maneuvers with low amplitudes were performed. The estimated aileron control effectiveness was monitored and the procedure was repeated until the aircraft reached a velocity of $170 \mathrm{kt}$. During this procedure, RAPIT was used to estimate e.g. the aileron control effectiveness derivative. Time series plots in Figure 13 show the corresponding results during one aileron step excitation (SLD I configuration). The top graph shows the control surface deflections of aileron, rudder and roll spoilers, directly below the related roll and yaw rate are given. In the last graph on the bottom of Figure 13 the progress of the estimation of the aileron control derivative is shown. Red stars mark the estimated aileron control derivative and error bars indicate a $95 \%$ confidence interval. Before the maneuver the estimated values were far off the reference value, because the algorithm did not have any a-priori knowledge about the aircraft's aerodynamic characteristics. After the maneuver the estimates converged towards a constant value, close to the reference. As the SLD I case was not expected to show a significant change in aileron effectiveness, the results might proof that the tool is well applicable for real time aircraft monitoring.

The aircraft performance during the flight test was monitored using the FITLAB-Online tool while identifying a first version of the simulation model in parallel. Due to flight safety reasons the pilots handled the aircraft very carefully especially during the first SLD flight (angle of attack range from 0 to 5 deg). Figure 14 shows the lift curve and drag polar for several 3-2-1-1 maneuvers from flight data and after identification in comparison to the basic aircraft's aerodynamics resulting from the same flight conditions and excitation. The aircraft was operated only in the linear region of the lift curve during these maneuvers and no measureable nonlinear lift curve slope change compared to the clean aircraft could be observed.

FIGURE 13 Online estimation of the aileron efficiency with RAPIT during an aileron step input.
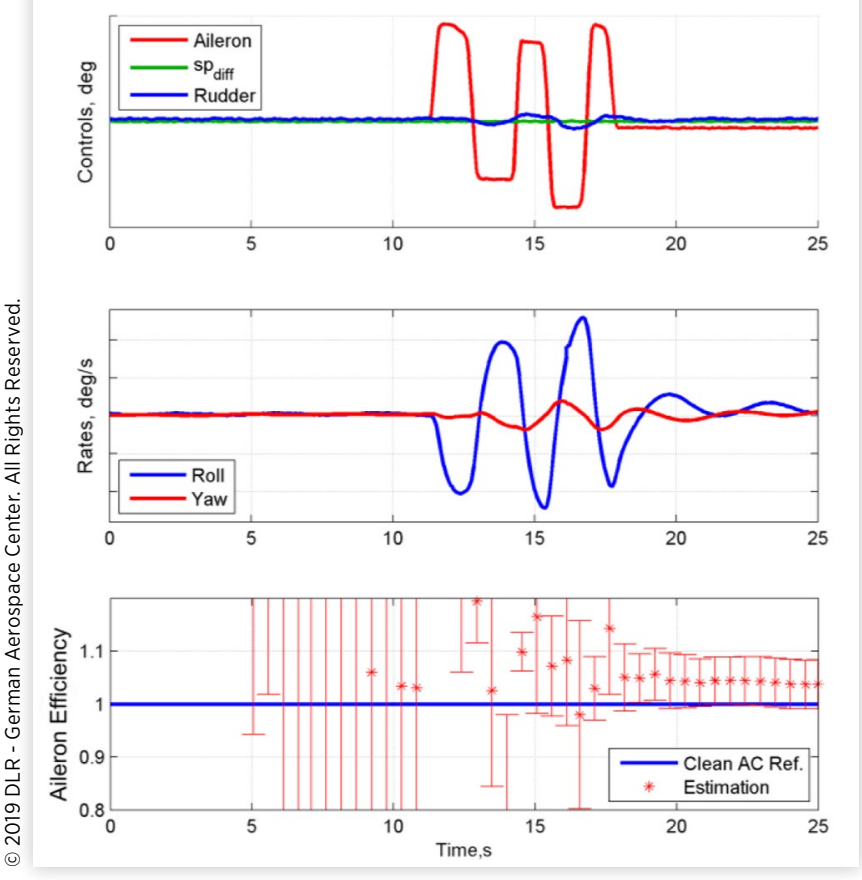

(c) 2019 DLR - German Aerospace Center. All Rights Reserved.
FIGURE 14 SLD I lift curve and drag polar (blue: flight test measurement / black: model clean / red: simulation after online icing model identification).

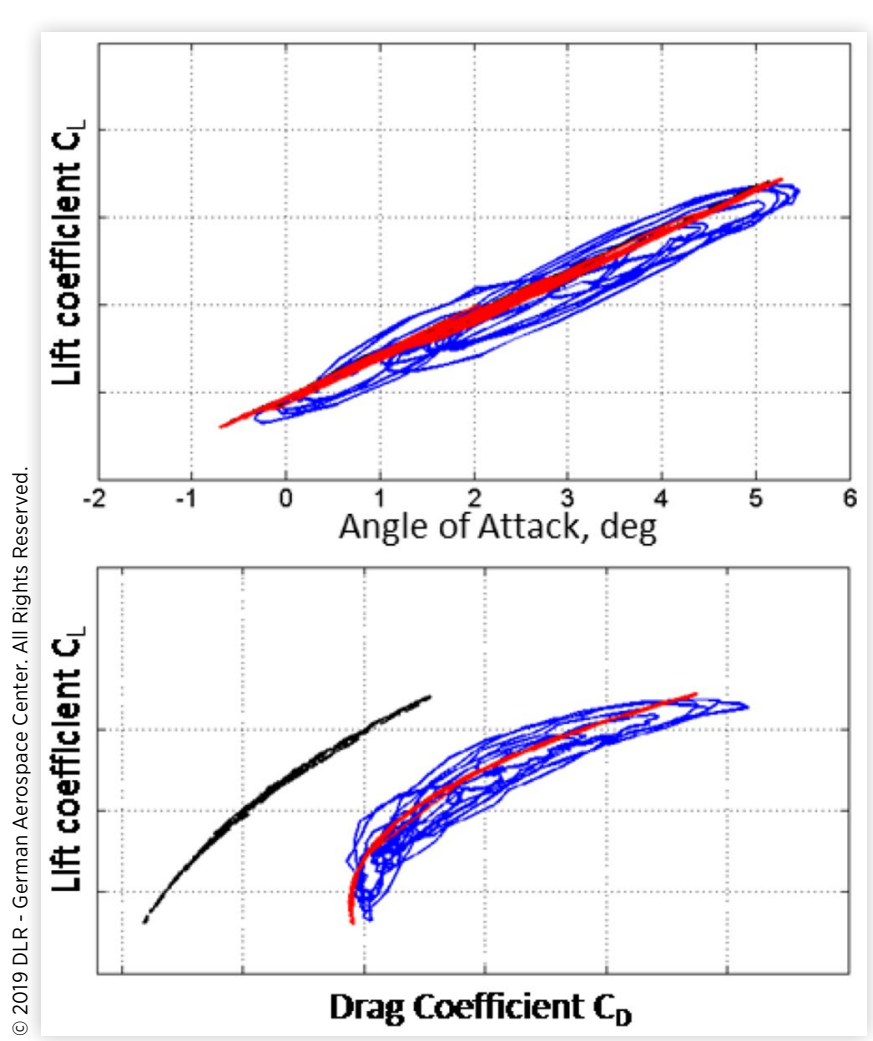

The fact that there is not necessarily a significant change of the linear lift curve due to icing at lower angles of attack is consistent with the findings in literature [3] . But the calculated and identified drag polar shows the expectable higher zero lift drag (98\% increase) and slightly changed curvature even at these low angles of attack.

By using the FITLAB-Online and RAPIT tool complete information about the change of aircraft characteristics in form of aerodynamic model derivative changes were available directly after the test flights and the results could be discussed during the debriefing.

\section{Post-Flight Data Analysis}

After the campaign, the whole flight test data was segmented and processed for the subsequent analysis and system-identification. The three different SLD-ice configurations were evaluated individually and the results compared afterwards.

\section{SLD I Configuration}

To identify parameters of the aerodynamic $\Delta$-model for the first, low-risk SLD-ice flight 30 data segments with approximately $564 \mathrm{~s}$ of flight time were used. For example, the drag curve is calculated from these data and plotted together with base aircraft's drag in Figure 15 (similar to the visualization of App.C flight tests in Figure 5). The plot shows that the flight 
FIGURE 15 Drag polar computed from measurements as a result of flight test maneuvers with SLD I configuration

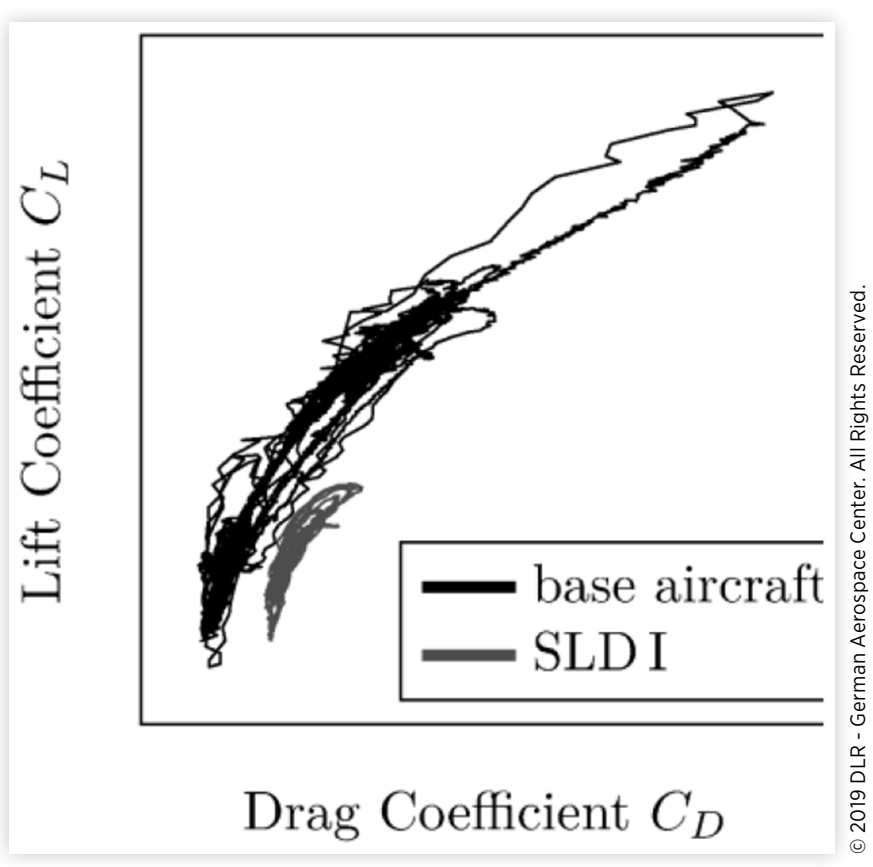

test data covers only the lower angle-of-attack region respectively only lower lift coefficients. But the effects of the SLD-ice are clearly visible: the zero-lift drag noticeably increases and the stronger curvature of the drag curve indicates a beginning flow separation far below the base aircraft's maximum angle of attack. The lift curve (not shown) reveals a slightly lower slope and also a change in the zero-lift angle of attack. These effects correspond to the general expectations from CFD calculations and wind tunnel tests for the SLD-ice cases.

\section{SLD II Configuration}

The second test flight provided data for an SLD-ice case well comparable to flight one with the exception that ice shapes were also attached in front of the ailerons. For parameter estimation 45 maneuvers with a total recording time of approximately $1365 \mathrm{~s}$ were extracted from the flight data recordings. The drag curve is also calculated from the flight data recordings and plotted together with base aircraft's drag in Figure 16. Similar to the first flight, only a lower angle-ofattack region (respectively low lift coefficients) is covered by the flight test data respectively the maneuvers executed. The relatively strong curvature of the drag polar indicates a beginning flow separation. This presumably occurs in the outer wing area because the additional ice shapes can significantly disturb the flow over the wing.

\section{SLD III Configuration}

The third flight was performed with the nominal SLD-ice configuration, which additionally include ice shapes on the engine pylons. But with the pylons having only a minor effect
FIGURE 16 Drag polar computed from measurements as a result of flight test maneuvers with SLD II configuration

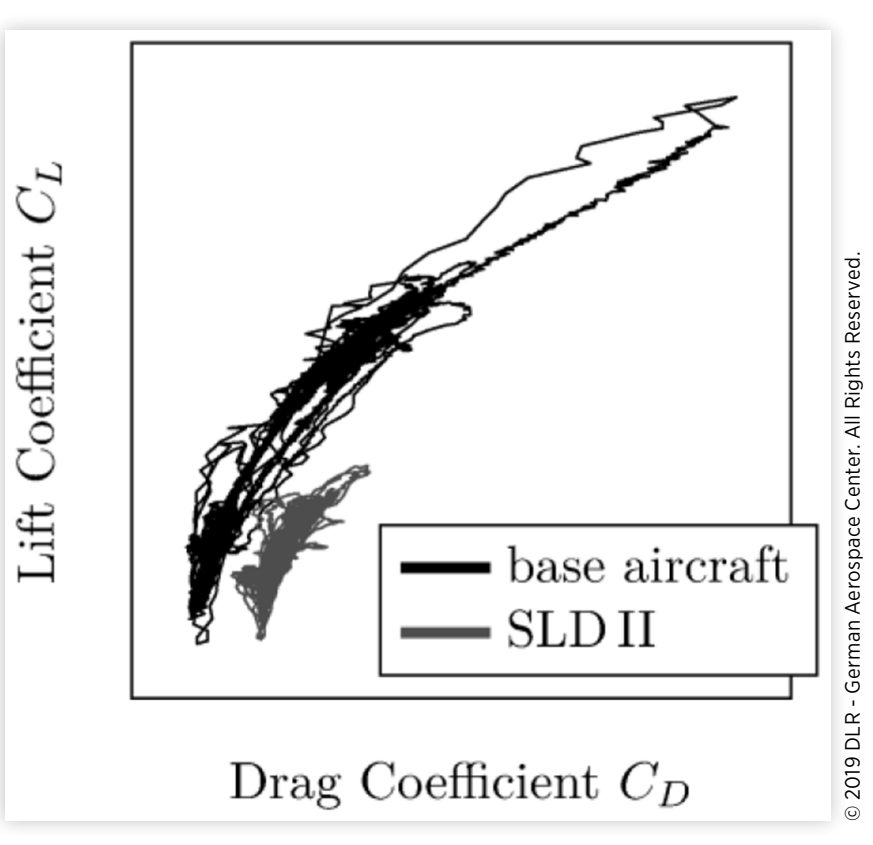

on the aerodynamic (lift) performance of the aircraft, it could be assumed that the main difference to second test flight (SLD II) would be an increase in drag. The data used for the further analysis contain 51 segments with around $1448 \mathrm{~s}$ of recorded flight time. The calculated drag polar is given in Figure 17. The angle of attack region flown is a little larger than in the previous flights. Therefore, the icing-induced change in the drag polar with the stronger curvature is more distinguished due to higher lift coefficients.

FIGURE 17 Drag polar computed from measurements as a result of flight test maneuvers with SLD III configuration

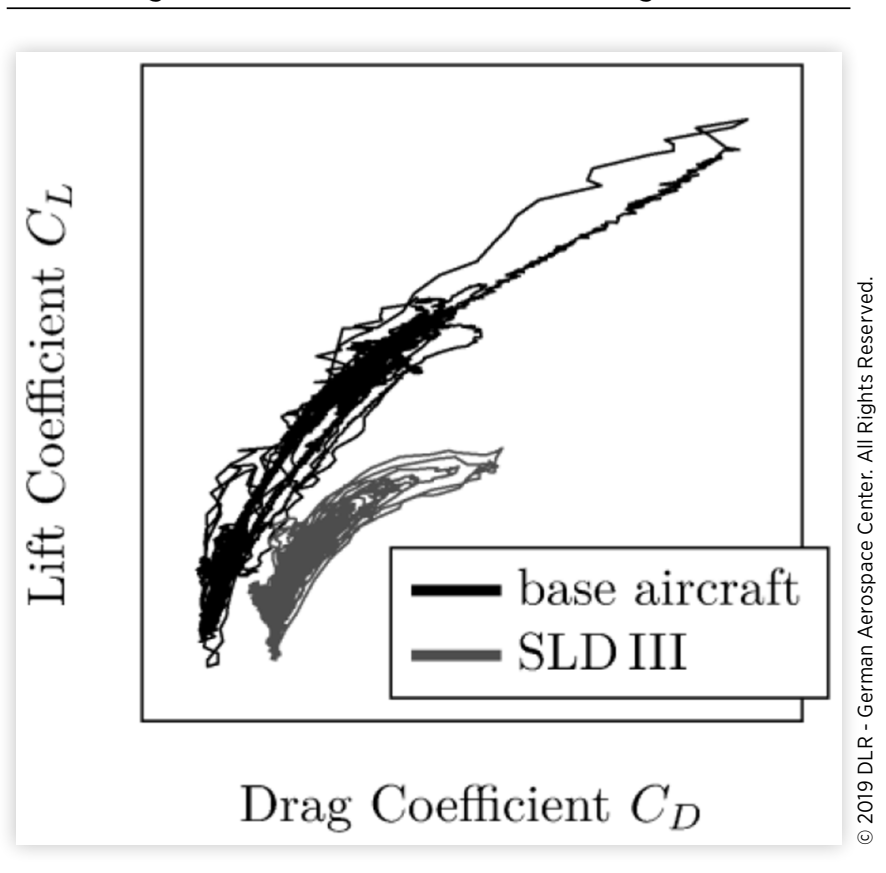

(c) 2019 DLR - German Aerospace Center. All Rights Reserved. 


\section{System-Identification Results}

With the different available flight data sets the $\Delta$-model structure presented in [18] was again used to identify parameters which allow suitably representing the change in aircraft aerodynamics for the different SLD-ice configurations. For the SLD I and II configuration the already existing model structure was well applicable: the simulation after identification perfectly matches the flight test data and the resulting parameters allow a physical interpretation of the revealed aerodynamic effects. But with the SLD III configuration having additional ice shapes on the engine pylons, an additional drag influence must be considered. Therefore, the $\Delta$-model structure [18] is extended by a part to consider this drag increase.

With this slight modification the model simulation results perfectly match the flight test measurements after parameter estimation. The resulting models were used to simulate the change in aircraft aerodynamics for comparison between the individual SLD configuration and with the App.C ice shapes. The results for each identified lift curve and drag polar are given in Figure 18. Basically, all noticeable changes of aircraft aerodynamics are well comparable with regard to aircraft lift and drag degradation. Furthermore, the changes of aerodynamics resulting from the different SLD-ice configurations are quite similar to the leading-edge ice shape degradation (App. C).

In detail, the individual results of parameter estimation and the flight data analysis reflect the slightly different aircraft characteristics for each SLD-ice configuration. The detectable drag change during the first flight of the campaign with the SLD I ice configuration was about $95 \%$ of the base aircraft's zero lift drag with a stronger curvature of the drag polar. The lift curve slope was only slightly reduced by $2 \%$ compared to the base aircraft. The premature flow separation at angles of attack far below the base aircraft's maximum angle of attack is similar to the behavior detected for the leading-edge ice case. The analysis of the data from the second flight (SLD II) with additional ice shapes in front of the ailerons revealed that the lift curve provides a slightly nonlinear behavior: during the model identification a slight kink in the lift curve at an angle of attack of around $4 \mathrm{deg}$ was found. This differs a little from the behavior in the SLD I case, but might be reasonable due to the fact that the additional ice shapes on the wing tip

\section{FIGURE 18 Changes of lift and drag curves for different} App. C and SLD-ice cases; aerodynamic model data (after identification)

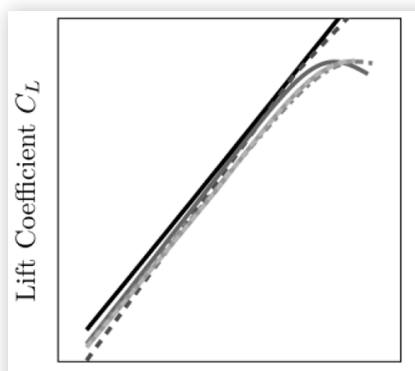

Angle of Attack $\alpha$

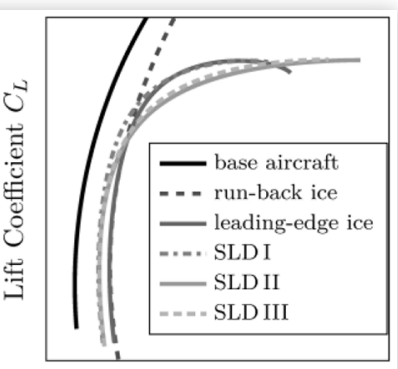

Drag Coefficient $C_{D}$

C 2019 DLR - German Aerospace Center. All Rights Reserved. disturb the flow over the wing and therefore influence the whole aircraft's lift characteristics. The predicted stall behavior of the aircraft with this ice configuration is similar to the SLD I case. The drag increase reflects the additional ice shapes due to a zero-lift drag increase of $98 \%$ with a stronger curvature of the drag polar. The third configuration flown during the flight test campaign differs from the SLD II configuration only by some additional shapes on the engine pylons. Therefore, there are no significant changes in the lift characteristic compared to SLD II detectable during the model identification, neither lift slope nor non-linear behavior representing the wing flow separation. The corresponding model parameters were consequently kept fixed on the values from previous analysis. But nevertheless, the pylons also produce vertical forces and a slight change of the aircraft pitching moment where detected during the identification. Also, there is a change of aircraft drag characteristics: the zero-lift drag increases by around $4 \%$ accompanied by a slight reduction the drag polar curvature.

The analysis of lateral aerodynamics revealed a change in the aircraft roll and yaw behavior for all configuration, which directly affects the aircraft roll mode and Dutch roll. But only small $2 \%$ reduction of the aileron efficiency was found in the data analysis. These results are similar to pilots' reports after the campaign: no significant change in relevant aircraft dynamics and handling qualities to safely operate the aircraft were noticeable during the flight. Nevertheless, note that there is a change in dynamics comparable to results given [25], but with the restrictions existing for the test flights (maintaining at low angles of attack and large safety margins) without any significant influence on the operation.

\section{Summary and Conclusions}

Due to the novel icing certification requirements for transport airplanes introduced by authorities with the App. O to e.g. CS-25, DLR and Embraer established a four year research cooperation on icing between 2012 and 2016. The main focus of this project was the evaluation of changed aircraft characteristics due to icing with certain regard on SLD effects. In contrast to other projects on SLD-icing, the cooperation was mainly driven by flight tests and the subsequent data analysis. In addition, two different new tools to monitor the aircraft characteristics during the flight test and consequently support and ease the flight test execution were developed and tested during the project.

Within the joint project, two different flight test campaigns with a Phenom 300 prototype (clean aircraft and with artificial SLD-ice shapes) were conducted and the resulting data was analyzed together with previously existing data from flight test with App.C ice shapes. The comparison of these unique flight test results led to several conclusions on icing effects on a distinct aircraft. In general, the results show the expectable degradation on aircraft performance due to a significant increase in aircraft drag, which has a different magnitude depending on the distinct ice-configuration: in case of the App. C ice shapes, the zero-lift drag increase is higher than for the tested SLD-shapes, but the drag increase 
for the latter is significantly higher for medium and higher lift coefficients respectively angles of attack. In contrast to the uniform change of flight performance and longitudinal aircraft aerodynamics for all investigated ice configurations (App. C and O) the change of lateral aircraft dynamics shows different case-dependent results. But nevertheless, for all configurations, no significant change of aircraft dynamics leading to a degradation of handling qualities could be detected for that specific aircraft. These results were well comparable to the pilot assessments of aircraft behavior during the individual test flights. Even so, icing does degrade the aircraft characteristics and the SLD-ice is not less critical for safe aircraft operations than the one formed by App. Cicing conditions. Furthermore, the usage of the developed tools for monitoring the aircraft characteristics during the flight test did indeed contribute to the safe conduction of flight as critical flight conditions were not entered.

For future work, the available data will be further analyzed to draw additional conclusions about SLD-ice effects on the Phenom 300, even so the dedicated research cooperation has officially ended. But, the results will also be used in the European Commission funded Horizon 2020 project SENS4ICE ("SENSors and certifiable hybrid architectures for safer aviation in ICing Environment", 2019-2022), which focusses on ice detection and will include a natural SLD-icing flight test campaign with the same flight test aircraft.

\section{References}

1. Green, S.D, "A Study of U. S. Inflight Icing Accidents and Incidents, 1978 to 2002," in 44th, AIAA Aerospace Sciences Meeting and Exhibit, Reno, Nevada, USA, Jan. 9-12, 2006, American Institute of Aeronautics and Astronautics, Inc. (AIAA), Paper No. AIAA 2006-82.

2. National Transportation Safety Board (NTSB), "Aircraft Accident Report (NTSB/AAR-96/01, DCA95MA001)," Safety Board Report, July 9, 1996, Washington, DC, USA.

3. Advisory Group for Aerospace Research \& Development (AGARD), "Ice Accretion Simulation. AGARD Advisory Report 344," Fluid Dynamics Panel Working Group 20, North Atlantic Treaty Organization (NATO), Neuilly-SurSeine, France, Dec. 1997.

4. Gray, V.H., "Prediction of Aerodynamic Penalties Caused by Ice Formations on Various Airfoils," Technical Note D-2166, National Aeronautics and Space Administration (NASA), Washington, D.C., USA, Feb. 1964.

5. Broeren, A.P., Whalen, E.A., Busch, G.T., and Bragg, M.B., "Aerodynamic Simulation of Runback Ice Accretion," Journal of Aircraft 47(3):924-939, May-June 2010.

6. Ranuado, R.J., Batterson, J.G., Reehorst, A.L. et al., "Determination of Longitudinal Aerodynamic Derivatives Using Flight Data from an Icing Research Aircraft," in 27th AIAA Aerospace Science Meeting, Reno, Nevada, USA, January 9-12, 1989, American Institute of Aeronautics and Astronautics, Inc. (AIAA), Paper No. AIAA 89-0754.

7. Ratvasky, T.P. and Ranuado, R.J., "Icing Effects on Aircraft Stability and Control Determined from Flight Data.
Preliminary Results," in 31st AIAA Aerospace Science Meeting and Exhibit, Reno, Nevada, USA, January 11-14, 1993, American Institute of Aeronautics and Astronautics, Inc. (AIAA), Paper No. AIAA 93-0398.

8. Lee, S.; Barnhart, B.P., and Ratvasky, T.P., "Dynamic WindTunnel Testing of a Sub-Scale Iced S-3B Viking," in AIAA Atmospheric and Space Environments Conference, Toronto, Ontario Canada, August 2-5, 2010, American Institute of Aeronautics and Astronautics, Inc. (AIAA), Paper No. AIAA 2010-7986.

9. Gingras, D.R., "Requirements and Modeling of in-Flight Icing Effects for Flight Training," in AIAA Modeling And Simulation Technologies (MST) Conference, Boston, Massachusetts, USA, August 19-22, 2013, American Institute of Aeronautics and Astronautics, Inc. (AIAA), Paper No. AIAA 2013-5075.

10. Jategaonkar, R.V., Flight Vehicle System Identification-A Time Domain Methodology, Second Edition, Volume 245 of Progress in Astronautics and Aeronautics (American Institute of Aeronautics and Astronautics, Inc. (AIAA), Reston, Virginia, USA, 2015).

11. Klein, V. and Morelli, E., Aircraft System Identification: Theory and Practice, AIAA Education Series (American Institute of Aeronautics and Astronautics, Inc. (AIAA), Reston, Virginia, 2006).

12. Raab, C., "Rapid Aerodynamic Parameter Identification on a Large Transport Aircraft," in AIAA SCITECH 2014, Atmospheric Flight Mechanics Conference, Jan. 13-17, 2014, National Harbor, Maryland, USA, American Institute of Aeronautics and Astronautics, Inc. (AIAA), ISSN:0021-8669.

13. Seher-Weiss, S., "FITLABGUI-A Versatile Tool for Data Analysis, System Identification and Helicopter Handling Qualities Analysis," in 42nd European Rotorcraft Forum, Lille, France, September 5-8, 2016.

14. Raab, C., Ohme, P., and Deiler, C., "Support of Icing Flight Tests by Near Real-Time Data Analysis," CEAS Aeronautical Journal 8(4):561-577, Dec. 2017, doi:10.1007/s13272-0170260-5.

15. Moennich, W., "Ein 2-Punkt-Aerodynamikmodell für die Identifizierung," in Proceedings of the 'Systemidentifizierung in der Fahrzeugdynamik' Symposium, Paper 3.1 in Deutsche Forschungs- und Versuchsanstalt fuer Luft- und Raumfahrt (DFVLR) Mitteilung, 1987, 87-22 (in German).

16. Fischenberg, D., "Identification of an Unsteady Aerodynamic Stall Model from Flight Test Data," in AIAA Atmospheric Flight Mechanics Conference, AIAA Paper 1995-3438, Aug. 1995, 138-146.

17. Jategaonkar, R., "Identification of the Aerodynamic Model of the DLR Research Aircraft ATTAS from Flight Test Data," in DLR-FB 90-40, Deutsche Forschungsanstalt für Luft- und Raumfahrt e. V. (DLR), Cologne, Germany, 1990.

18. Deiler, C., "Aerodynamic Modeling, System Identification, and Analysis of Iced Aircraft Configurations," Journal of Aircraft 55(1):145-161, 2017, doi:10.2514/1.C034390.

19. Hamel, P.G. and Jategaonkar, R.V., "Evolution of Flight Vehicle System Identification," Journal of Aircraft 33(1):9-28, Jan.-Feb. 1996, doi:10.2514/3.46898.

20. Jategaonkar, R., Fischenberg, D., and von Gruenhagen, W., "Aerodynamic Modeling and System Identification from 
Flight Data-Recent Applications at DLR," Journal of Aircraft 41(4):681-691, July-Aug. 2004, doi:10.2514/1.316.

21. Bragg, M.B. et al., "Effect of Ice Accretion on Aircraft Flight Dynamics," in 38th AIAA Aerospace Sciences Meeting and Exhibit, American Institute of Aeronautics and Astronautics, Inc. (AIAA), Reno, Nevada, USA, 2000, doi: 10.2514/6.2000-360.

22. Deiler, C., "Time Domain Output Error System Identification of Iced Aircraft Aerodynamics," CEAS Aeronautical Journal 8(2):231-244, 2017, doi:10.1007/s13272016-0231-2.

23. Deiler, C. and Kilian, T., "Dynamic Aircraft Simulation Model Covering Local Icing Effects," CEAS Aeronautical Journal, 2018, doi:10.1007/s13272-018-0291-6.

24. Fischenberg, D., "A Method to Validate Wake Vortex Encounter Models from Flight Test Data," in 27th International Congress of the Aeronautical Sciences, International Council of the Aeronautical Sciences (ICAS), Nice, France, 2010.

25. Deiler, C., "Flight Characteristics of Iced Aircraft," in AIAA SCITECH 2019, Atmospheric Flight Mechanics Conference, San Diego, California, USA, Jan. 7-11, 2019, American Institute of Aeronautics and Astronautics, Inc. (AIAA), 2019. Paper No. AIAA 2019-0560.

26. Circular, A., "Compliance of Transport Category Airplanes with Certification Requirements for Flight in Icing Conditions," AC 25-28, Federal Aviation Administration (FAA), USA, 2014.

27. Wright, W.B., "Validation Results for LEWICE 3.0," NASA/ CR-2005-213561, 2005.

28. Pueyo, A., "Efficient 3D Artificial Ice Shapes Simulations with 2D Ice Accretion Codes Using a 3-Level Correction," SAE Technical Paper 2013-01-2136, 2013, doi:10.4271/201301-2136.

29. Anderson, D.N. and Tsao, J., "Ice Shape Scaling for Aircraft in SLD Conditions," NASA/CR-2008-215302, 2008.

30. Lynch, F.T. and Khodadoust, A., "Effects of Ice Accretions on Aircraft Aerodynamics," Progress in Aerospace Sciences 37(8):669-767, Nov. 2001.

31. Broeren, A.P., Diebold, J.M., and Bragg, M.B., "Aerodynamic Classification of Swept-Wing Ice Accretion," NASA/TM2013-216381, 2013.
32. Domingos, R. and Silva, D., "3D Computational Methodology for Bleed Air Ice Protection System Parametric Analysis," SAE Technical Paper 2015-01-2109, 2015, doi: 10.4271/2015-01-2109.

33. Alègre, N. and Hammond, D., "Experimental Setup for the Study of Runback Ice at Full Scale," Journal of Aircraft 48(6):1978-1983, 2011, doi:10.2514/1.C031398.

\section{Contact Information}

\author{
Christoph Deiler \\ German Aerospace Center (DLR) \\ Institute of Flight Systems \\ Department Flight Dynamics and Simulation \\ Lilienthalplatz 7 \\ Braunschweig, 38108, Germany \\ christoph.deiler@dlr.de
}

\section{Definitions/Abbreviations}
DLR - German Aerospace Center
SLD - supercooled large droplets
FZDZ - freezing drizzle
FZRA - Freezing rain
MVD - Medium volume diameter
RAPIT - Rapid Aerodynamic Parameter Identification Tool
base - base/clean aircraft
ice - iced aircraft
$\mathrm{C}(\cdot)$ - aerodynamic model coefficient
$\mathrm{C}_{\mathrm{D}}$ - drag coefficient
$\mathrm{C}_{\mathrm{L}}$ - lift coefficient
$\mathbf{P}$ - aerodynamic model parameter
$\mathbf{k}_{\mathbf{p}}, \mathbf{d}_{\mathbf{p}}-\Delta$-model parameters
TWR - Thrust-to-weight ratio
$\mathrm{V}_{\text {IAS }}$ - indicated airspeed
$\boldsymbol{\alpha}$ - angle of attack

(c) 2019 DLR - German Aerospace Center. All rights reserved. Published by SAE International. No part of this publication may be reproduced, stored in a retrieval system, or transmitted, in any form or by any means, electronic, mechanical, photocopying, recording, or otherwise, without the prior written permission of the copyright holder(s).

Positions and opinions advanced in this work are those of the author(s) and not necessarily those of SAE International. Responsibility for the content of the work lies solely with the author(s). 